\title{
Mineral dust: Meteorological controls and climate impacts
}

\author{
Kerstin Schepanski', U. Merkel² and I. Tegen
}

\begin{abstract}
Dust contributes substantially to the aerosol load of the atmosphere, but lifting dust high above the ground requires specific meteorological conditions. Once mobilized, dust interacts with components of the Earth system in multifaceted ways, which causes modifications to the energy budget and ecosystems.
\end{abstract}

Bare land surfaces are the main sources for mineral dust. The most active and strongest dust sources are predominantly situated in semi-arid and arid regions at sub-tropical latitudes where subsiding air masses stabilize the atmosphere and dry climates prevail. In terms of dust emission flux and frequency of emission events, the Sahara Desert is considered the world's largest dust source, although the spatio-temporal variability and characteristics of its dust production are yet not fully understood.

Dust uplift and entrainment into the atmosphere are determined by surface wind speeds and local land surface characteristics such as soil texture, soil moisture, and vegetation (Fig. 1). Dust emission is often described as a threshold problem, where particles are only entrained when wind speeds rise above a certain threshold transferring momentum from the atmosphere to the dust particles. The wind speed required for entrainment depends on soil characteristics (e.g. Marticorena and Bergametti 1995) such as particle shape, size and density, and inter-particle binding energy.

In addition to the atmospheric control on dust emission, land surface characteristics also play a role by determining the dust source's erodibility. Relative to atmospheric conditions, the land surface characteristics of dust sources remain fairly constant. Thus, the predominance of specific land surface conditions, such as smooth surfaces and the presence of fine and loose soil particles, is an important aspect in determining its erodibility. In particular, alluvial sediments are prone to wind erosion and play a significant role in many dust sources today and in the past (Reheis and Kihl 1995). As fresh layers of fluvial sediment deposits tend to occur in response to strong precipitation events such as flash floods, dust emission from this source type are characterized by more pronounced interannual variability.

\section{Meteorological settings for dust emission} The processes contributing to dust source activation vary between seasons due to seasonal changes in atmospheric circulation patterns. Besides land surface characteristics, understanding the meteorological aspects of atmospheric conditions which provide sufficient wind (momentum) for dust uplift is crucial when discussing the dust cycle today, but also during ancient times and for future scenarios.

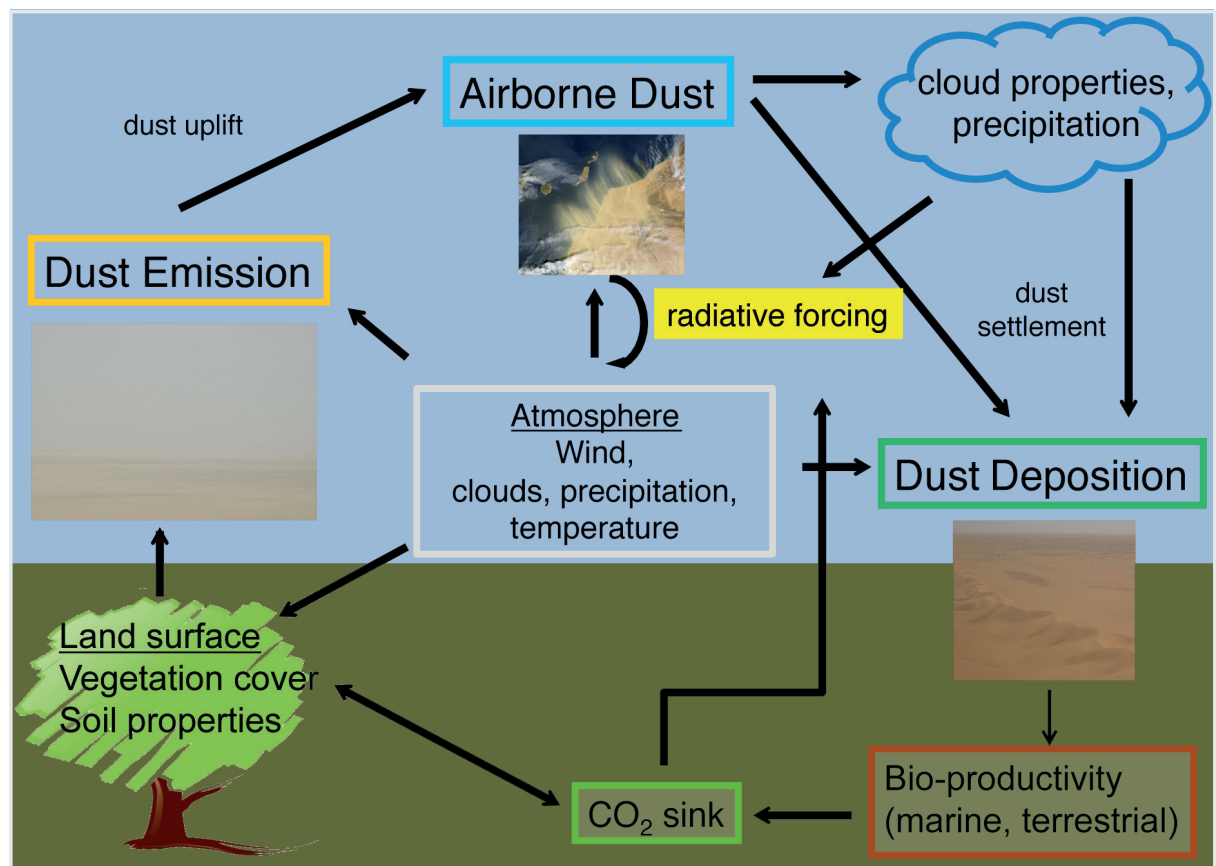

Figure 1: The atmospheric dust cycle and related feedback mechanisms

Recent studies analyzing satellite data and model simulations have identified different meteorological settings that play a key role in creating suitable atmospheric conditions for dust uplift (Schepanski et al. 2009). Satellite observations at 15 -minute resolution revealed a strong diurnal cycle in the onset of dust emission and, integrated over months, synoptic climate patterns that result in dust uplift (Fig. 2). In terms of frequency and associated dust emission fluxes, the following meteorological processes are suggested: (1) downward mixing of the nocturnal low-level jet (LLJ), (2) cold pools induced by moist convection, and (3) baroclinicity and cyclogenesis.

A sudden and strong increase in surface wind speed occurs in the vicinity of a decaying nocturnal LLJ. LLJs are characterized by a low-level ( 200-700 $\mathrm{m}$ above ground) wind speed maximum that forms due to the frictional decoupling of upper air layers from the surface air layers at night. These preconditions are frequently fulfilled during calm nights. Nocturnal LLJs usually begin to form before midnight and accelerate during the second half of the night. After sunrise, convective turbulence increases due to solar heating and erodes the nocturnal temperature inversion. Consequently, the LLJ layer is frictionally coupled to the surface layer and momentum from the LLJ is mixed downward leading to wind gusts and increased surface wind speeds, ultimately uplifting dust particles after sunrise when the resulting winds are strong enough. Nocturnal LLJs are a frequent phenomenon over North Africa and can explain a major fraction of observed dust source activations in space and time.

Cold pools, also described as downdrafts or gravity (density) currents, are initiated by deep convection. Evaporative cooling creates pools of cold air that subsides due to its higher density compared with the surrounding air. At the ground, the downward motion is transformed into a horizontal motion and the air mass spreads out horizontally forming a gust front. High surface wind speeds following the front can uplift dust and build an arcus-like dust front, a so-called Haboob. Although high dust emission fluxes are achieved during the passage of such a gust front, such dust emission events are less frequent than that from LLJs due to the rare occurrence of cold pools. 

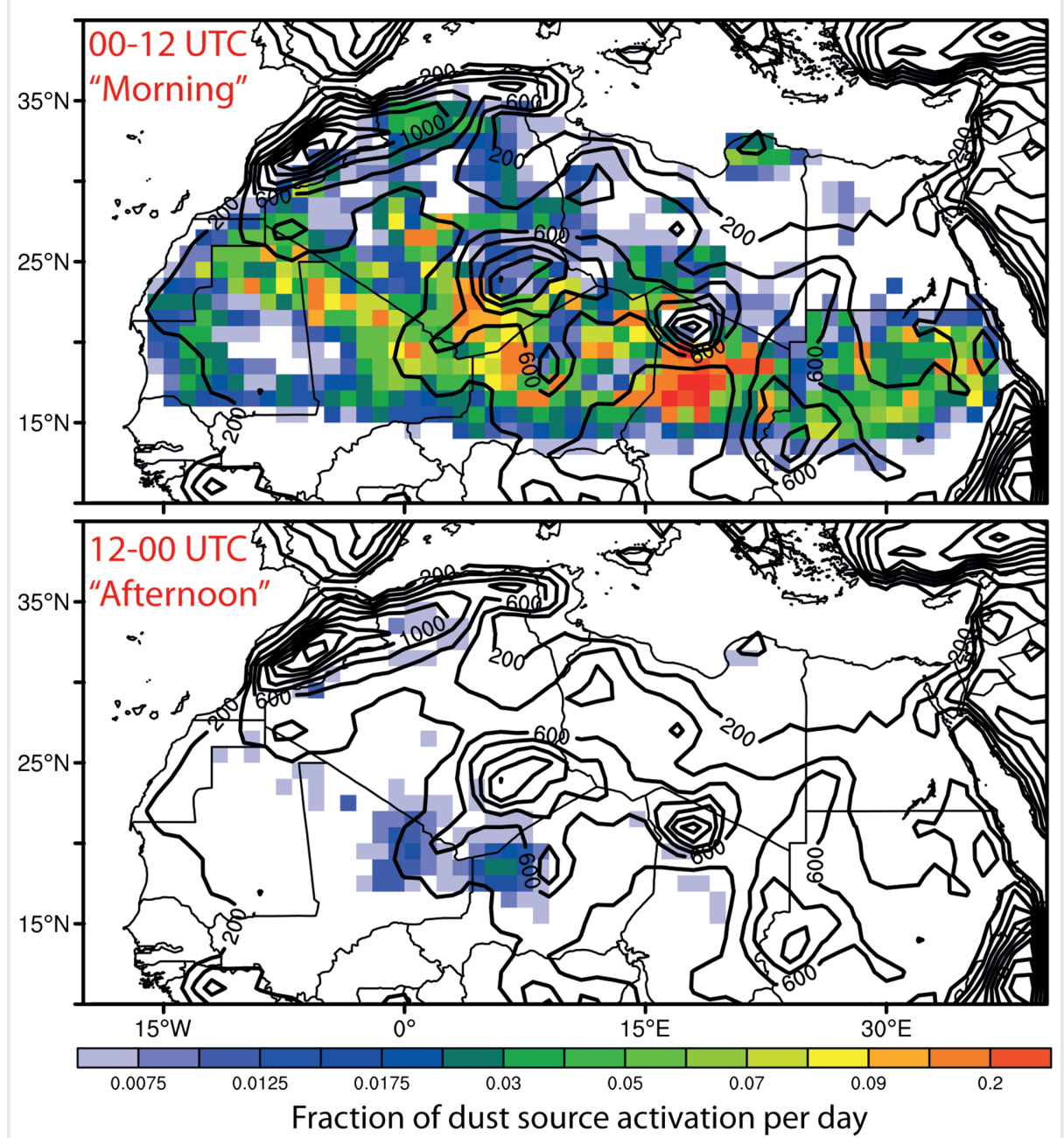

Figure 2: Diurnal variability of dust source activations over North Africa inferred from MSG-SEVIRI IR dust imagery for 2006-2010 following Schepanski et al. (2009). Figures shows the occurrence frequency of dust source activations in the first (top panel) and second (bottom panel) half of the day. Orography is given by contour lines.

Strong surface wind fields also form in association with baroclinic disturbances and cyclonic systems, predominantly during boreal spring. Prominent examples are the cold outbreaks of Arctic air masses over China that result in dust fronts originating from the Gobi Desert, and Mediterranean cyclones which form dust fronts over Mediterranean North Africa and the Middle East.

\section{Climate impacts of dust}

The relevance of mineral dust for the modern climate system has been widely studied, most often from an atmospheric perspective through its impact on the radiative balance and on clouds. Dust impacts the radiation balance of the Earth by scattering and absorbing incoming solar radiation, and by absorbing and emitting terrestrial radiation. Net radiative forcing by dust depends on the optical properties of the particles, which in turn depend on their size distribution and mineral composition. The magnitudes and even the sign of the net radiative forcing at the top of the atmosphere by dust from both natural desert sources and anthropogenic (agricultural) land surfaces are highly uncertain. The uncertainty of estimates of global annual average forcing is in the order of $1-2 \mathrm{Wm}^{-2}$ at the Earth surface (Carslaw et al. 2010).
Dust also provides nuclei for ice particle formation in the atmosphere and thus impacts the microphysical properties and the lifetimes of mixed-phase and ice clouds, and the kind and frequency of precipitation.

Dust now receives increasing attention from an Earth system perspective (Shao et al. 2011) since mineral dust interacts with different components of the Earth system (Fig. 1). For instance, the deposition of mineral dust on glaciers has the potential to lower their surface albedo, enhance their melt rates, and speed up their retreat (Oerlemans et al. 2009). This process and positive feedback mechanism may also have played an important role during Pleistocene deglaciations (Ganopolski et al. 2010).

The marine realm is also affected by mineral dust deposition. Downstream of major west African dust sources, tropospheric mineral dust cools the Atlantic ocean surface and mixed layer by $0.5-2^{\circ} \mathrm{C}$ in response to an increase in the aerosol optical depth (Evan et al. 2009; Martínez Avellaneda et al. 2010). Furthermore, Atlantic hurricane formation, could be reduced in response to two effects: (1) The dust's cooling effect on the surface ocean reduces the energy for strong atmospheric convection and (2) increased wind shear due to heating of air layers containing dust might impede the development of cyclonic cells. However, an unambiguous causal relationship has not yet been proven with sufficiently good data.

Through its impact on ocean surface temperatures and its modification of land-sea contrasts, dust may also feed back on the hydrological cycle, and thus on vegetation dynamics. In turn associated changes in land surface conditions modify the dust mobilization potential of source areas. Superimposed on the natural dust variations, current and future anthropogenic land is altering the geographical distribution of preferential dust mobilization, although quantitative estimates of projected human-induced dust changes are highly uncertain (Mahowald et al. 2009).

Dust also impacts biogeochemical cycles. Over land, desert dust influences soil conditions in various ecosystems through phosphorous deposition. In the ocean, dust has been found to enhance marine productivity by iron fertilization (Jickells et al. 2005; Martínez-García and Winckler, this issue) and has been argued to increase particle settling rates through ballasting, i.e. the adhesion of organic matter to sinking mineral particles. This affects the ocean carbon cycle by enhancing organic carbon export from the surface to the deep ocean (Iversen et al. 2010; Ternon et al. 2010).

\section{Perspectives}

Geological records from ice cores, ocean sediments and loess deposits provide information about dust deposition in past climates. However, from a paleo-perspective, dust-relevant processes operate on extremely short timescales and relatively small spatial scales. Nevertheless, these processes are embedded in the large-scale background climatic state and low-frequent variations of the climate system, in addition to playing an important role through various feedbacks, e.g. the dustsnow-albedo effect, or the link to the ocean biological pump. Therefore, the geologic dust research should be flanked by modeling efforts which realistically implement the processes controlling dust emission, transport and deposition into global Earth system models to provide the required spatio-temporal context for the interpretation of the proxy evidence.

\section{AFFILIATIONS}

'Leibniz Institute for Tropospheric Research, Leipzig,

Germany

${ }^{2}$ MARUM, Bremen, Germany

\section{CONTACT}

Kerstin Schepanski: schepanski@tropos.de

\section{REFERENCES}

Full reference list under:

www.pages-igbp.org/products/magazine/ref2014_2.pdf Evan AT et al. (2009) Science 324: 778-781

\section{Ganopolski A et al. (2010) Clim Past 6: 229-244}

Mahowald NM et al. (2009) Ann Rev Mar Sci 1: 245-278

Schepanski K et al. (2009) J Geophys Res 114, doi:10.1029/2008JD010325

Shao Y et al. (2011) Aeolian Res 2: 181-204 